\title{
Instrumental escape as a function of UCS intensity, UCS reduction, and type of instructions'
}

A key-tapping escape response was conditioned using 115 , 95 , or $65 \mathrm{db}$ sound intensity for 90 trials. When given explicit instructions $S$ s were told that faster key tapping led to faster sound reduction. When given implicit instructions Ss were told only that key tapping was necessary when the sound was on. Response speed was faster with explicit rather than implicit instructions, and significantly faster at $115 \mathrm{db}$ intensity as compared to 95 or $65 \mathrm{db}$ intensities. The $95 \mathrm{db}$ and $65 \mathrm{db}$ groups did not differ significantly in performance. Further, a reduction in the magnitude of reward from complete reduction to only $20 \mathrm{db}$ reduction for half of the $S s$, after trial 45 , produced no reliable change in performance.

In recent years several investigators have examined the role of sound as a UCS in escape conditioning using animals (Barnes \& Kish, 1957; Barry \& Harrison, 1957; Campbell, 1955; Campbell, 1957; Harrison \& Abelson, 1959), but relatively few investigators have examined human escape performance to sound (Azrin, 1958; Porter \& Blanchard, 1963). Both Azrin and Porter and Blanchard have shown that a strong auditory stimulus may serve as an effective UCS, and that the reduction of this UCS serves to reinforce. However, unlike animal studies, changes in the amount of reward have not been effective in modifying behavior. The present study served to extend the work of Porter and Blanchard to a new response task, key-tapping, to reexamine the effects of changes in amount of UCS reduction after completion of a $\mathrm{CR}$, and the effects of two degrees of conditioning information provided by instructions.

\section{Method}

One-hundred and eighty general psychology students were used. Of these Ss, 144 were assigned to four groups of $36 \mathrm{Ss}$ each in a 2 by 2 factorial design. Factors were explicit versus implicit instructions, and $115 \mathrm{db}$ versus $95 \mathrm{db}$ UCS intensities. The $1000 \mathrm{cps}$ square wave UCS was delivered to a pair of $600 \mathrm{ohm}$ headphones by an EICO sine/square wave generator. The presentation of the UCS was controlled by an interval programmer and the attenuation of the UCS by a Hewlett-Packard Audio Attenuator, while the duration of the attenuated stimulus was controlled by an interval timer. The response button was connected to a predetermining counter which actuated both the timer and attenuator.

After being seated in front of the table containing the response key, $\mathrm{S}$ received one of two sets of instruc- tions from $\mathrm{E}$. With explicit instructions $\mathrm{S}$ was told that the faster he/she tapped the key, the sooner the sound would terminate. With implicit instructions, Ss were told only to key tap when the sound came on. All Ss received 90 trials of 20 key taps each, at intervals of 7,9 , or 11 sec., randomly varied. A trial consisted of the onset of the UCS, followed by 20 key taps, which resulted in the reduction of the UCS to background noise level-50-55 db. On trials 46-90 half of each experimental group received complete reduction of the UCS to background noise level as before, while the remaining half of each group received only $20 \mathrm{db}$ of UCS reduction after the 20 key taps. This reduced UCS remained on for $3 \mathrm{sec}$. after responding, and was then reduced to background noise level. Thus, for trials $46-90$ a 2 by 2 by 2 factorial design was used with 18 Ss per group. In addition to the eight experimental groups, two baseline control groups of $18 \mathrm{Ss}$ each, received a $65 \mathrm{db}$ square wave. For 90 trials one group received explicit instructions, the other implicit instructions. The $65 \mathrm{cb}$ value was chosen because it had minimal motivating properties. Results and Discussion

Figure 1 presents the mean reciprocal time required to complete each trial of 20 key taps in blocks of five trials. Asymptotic performance at the completion of

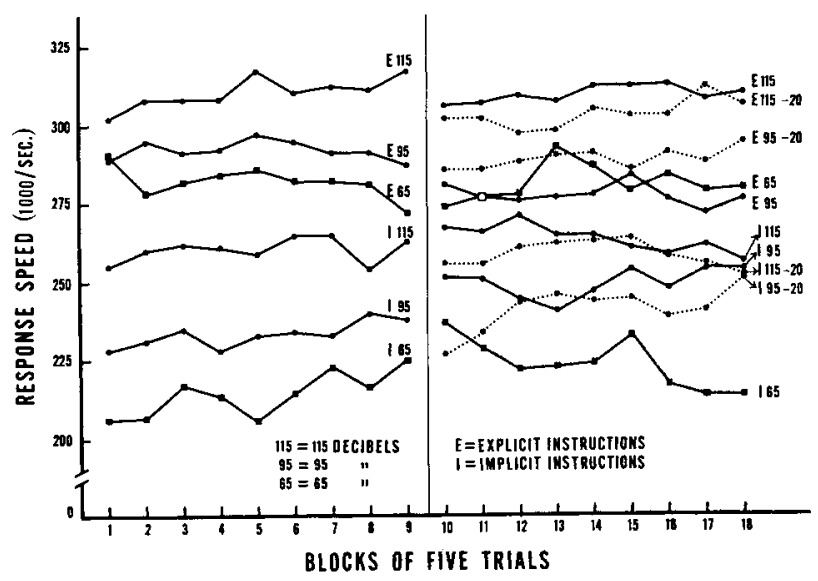

Fig. 1. Mean response speed in blocks of five trials. The vertical line indicates the split in the experimental groups after trial 45. The $-\mathbf{2 0}$ is used after those groups which received only $20 \mathrm{db}$ reduction after trial 45 . 
the first 45 trials was examined via a factorial analysis of variance over trials 26-45. Explicit instructions led to significantly higher response speeds than implicit instructions, $F=75.38, d f=1 / 174, p<.001$. Performance was also an increasing function of UCS intensity, $F=10.52$, df $=2 / 174, p<.001$. Dunnett's test (Winer, 1962, pp. 89-92) was used in order to compare the performance of the explicit and implicit $65 \mathrm{db}$ baseline control groups with the $115 \mathrm{db}$ and $95 \mathrm{db}$ groups. There was no significant difference in performance between the two $65 \mathrm{db}$ groups and their respective $95 \mathrm{db}$ groups; however, both the explicit and implicit 115 groups performed significantly faster than their corresponding control groups; $t=2.63, \mathrm{df}=136$, $p<.02$, and $t=3.38, d f=136, p<.01$ respectively.

Turning to performance over trials $46-90$, a threefactor analysis was performed over trials 71-90. The two baseline groups were not included in this analysis in order to avoid an incomplete factorial design. Subsequently, the baseline groups were compared against their appropriate experimental groups in a separate analysis. As is apparent from Fig. 1, explicit instructions led to significantly faster performance than implicit instructions, $F=30.68, \mathrm{df}=$ $1 / 136, p<.001$. Further, the $115 \mathrm{db}$ condition led to significantly faster performance than the $95 \mathrm{db}$ condition, $F=4.53, \mathrm{df}=1 / 136, \mathrm{p}<.05$. However, the effects of the $20 \mathrm{db}$ of UCS reduction versus complete reduction of the UCS were not significant, nor were any of the interactions reliable. Using Dunnett's test, none of the explicit groups differed reliably in performance from their baseline group. However, with implicit instructions both the 115-0 and 115-20 groups performed significantly faster than their baseline groups; $t=2.73, \mathrm{df}=85, \mathrm{p}<.05$, and $t=2.59, \mathrm{df}=85$, $\mathrm{p}<.05$ respectively.

The most striking result of this study was the large increase in performance obtained by a minimal change in instructions. The reasons for the magnitude of this effect are unclear since, regardless of instructions, the simplicity of the response task should have made response contingencies clear. While the present results do indicate that intense sound is effective in enhancing escape performance in a fashion similar to shock, the similar performance of the $95 \mathrm{db}$ UCS and $65 \mathrm{db}$ UCS groups indicates the relatively narrow range over which an intense auditory stimulus serves as an effective UCS. From 115 to $100 \mathrm{db}$ seems to be the effective UCS range in this situation, and agrees with Campbell's (1955) animal work. Thus intensities greater than $115 \mathrm{db}$ risk ear damage, while any less than $100 \mathrm{db}$ do not seem to differentially affect performance.

Like the Porter and Blanchard (1963) study, a change in reward magnitude in this study did not exert a significant effect on performance, unlike Campbell's (1955) study of escape behavior using sound. Possibly the relatively short duration of the reduced stimulus used as reward was insufficient to modify performance, or the relatively narrow range of sound intensities serving as an effective UCS also implies a very narrow range of intensities that can serve as a reward.

\section{References}

Azrin, N. H. Some effects of noise on human behavior. J. exp. Anal. Behav., 1958, 1, 183-200.

Barnes, G. W., \& Kish, G. B. Reinforcing properties of the termination of intense auditory stimulation. J. comp. physiol. Psychol., 1957, 50, 40-43.

Barry, J. J., Jr., \& Harrison, J. M. Relation between stimulus intensity and strength of escape responding. Psychol. Rep., 1957, $3,3-8$.

Campbell, B. A. The fractional reduction in noxious stimulation required to produce "just noticeable" learning. J. comp. physiol. Psychol., 1955, 48, 141-148.

Campbell, B. A. Auditory aversion thresholds of rats for bands of noise. Science, $1957,125,596-597$.

Harrison, J. M., \& Abelson, R. M. The maintenance of behavior by the termination and onset of intense noise. J. exp. Anal. Behav., $1959,2,23-42$.

Porter, J. J., \& Blanchard, R. J. Instrumental escape conditioning using an auditory UCS. Psychol. Rep., 1963, 12, 223-226.

Winer, B. J. Statistical principles in experimental design. New York: McGraw-Hill, 1962.

\section{Note}

1. This research was supported in part by grants UW-63-603 and NIMH MH10648-01 to the senior author. 